\title{
COMPLEX ANALYSIS OF IONOSPHERIC RESPONSE TO OPERATION OF PROGRESS CARGO SPACECRAFT FROM GNSS DATA IN THE BAIKAL REGION
}

\author{
A.B. Ishin \\ Institute of Solar-Terrestrial Physics SB RAS, \\ Irkutsk, Russia, ishin@iszf.irk.ru, levasan@mail.ru \\ S.V. Voeykov \\ Institute of Solar-Terrestrial Physics SB RAS, \\ Irkutsk,Russia,serg@iszf.irk.ru
}

\author{
N.P. Perevalova \\ Institute of Solar-Terrestrial Physics SB RAS, \\ Irkutsk, Russia,pereval@iszf.irk.ru

\section{V.V. Khakhinov} \\ Institute of Solar-Terrestrial Physics SB RAS, \\ Irkutsk,Russia, khakhin@iszf.irk.ru
}

\begin{abstract}
As part of the Plasma-Progress and RadarProgress space experiments conducted from 2006 to 2014, effects of the Progress spacecraft engines on the ionosphere have been studied using data from Global Navigation Satellite System (GNSS) receivers. 72 experiments have been carried out. All these experiments were based on data from the International GNSS Service (IGS) to record ionospheric plasma irregularities caused by engine operation. 35 experiments used data from the ISTP SB RAS network SibNet. The analysis of the spatiotemporal structure of total electron content (TEC) variations has shown that the problem of identifying the TEC response to engine operation is complicated by a number of factors: 1) the engine effect on ionospheric plasma is strongly localized in space and has a relatively low intensity; 2) a small number of satellite-receiver radio rays
\end{abstract}

due to the limited number of GNSS stations, particularly before 2013; 3) a potential TEC response is masked with background ionospheric disturbances of various intensities. However, TEC responses are identified with certainty when a satellite-receiver radio ray crosses a disturbed region within minutes after the impact. TEC responses have been registered in 7 experiments (10\% of cases). The amplitude of ionospheric response (0.3-0.16 TECU) exceeded the background TEC variations ( 0.25 TECU) several times. The TEC data indicate that the ionospheric irregularity lifetime is from 4 to 10 minutes. According to the estimates we made, the transverse size of irregularities is from 12 to $30 \mathrm{~km}$.

Keywords: ionosphere, GNSS, SibNet, Progress.

\section{INTRODUCTION}

Active experiments on the impact of CS engines on ionospheric plasma are of great interest because first they can be repeated to compare and verify results and second they represent a calibrated local effect that can be used to compare the accuracy of different diagnostic tools, to refine ionospheric models, and to test hypotheses on interaction between different atmospheric layers.

Active space experiments (SE) Plasma-Progress and Radar-Progress [Lebedev et al., 2008; Potekhin et al., 2009; Khakhinov et al., 2013], conducted at the Institute of Solar-Terrestrial Physics of the Siberian Branch of the Russian Academy of Sciences (ISTP SB RAS) from 2006 to 2014, were aimed at studying the impact of Progress cargo spacecraft (CS) engines on the upper atmosphere and the ionosphere [Khakhinov et al., 2011, 2012; Borisov et al., 2012; Khakhinov et al., 2010, 2012]. For the experiments, CS engines were started after undocking from the International Space Station (ISS) when the spacecraft flied over ISTP SB RAS observatories [Khakhinov et al., 2011, 2012; Khakhinov et al., 2012]. Conditions in near-Earth space were monitored with an ISTP SB RAS array of geophysical instruments [Seismoionospheric ..., 2012 ; Institute ..., 2015 ]. One of these instruments is the GLOBDET hardware and software system developed at ISTP SB RAS [Afraimovich, Perevalova, 2006], designed to identify ionospheric disturbances of natural and anthro- pogenic origin in measurements of total electron content (TEC) variations. The measurements are made using signals from Global Navigation Satellite Systems (GNSS). GLOBDET data are acquired with a ground GNSS dual-frequency receiver network. In 2006-2012, ionospheric effects of Progress CS engines were detected with GNSS receivers included in the International GNSS Service (IGS). In 2012, ISTP SB RAS deployed its own regional network of GNSS ground receiving stations (SibNet) [Ishin et al., 2017]; therefore, in 20132014, data from this network were used. In this paper, we analyze in detail the ionospheric response to the operation of approach-correction engines (ACE) of Progress CS, which manifests itself in TEC. This analysis is based on GNSS data.

\section{CALCULATION OF THE TOTAL ELECTRON CONTENT FROM GNSS DATA}

In order to determine exact coordinates of a receiver, a GNSS satellite emits continuous signals at two carrier frequencies $f_{1}$ and $f_{2}$. For the same purpose, the receiver measures the distance $D$ to the GNSS satellite from time of navigation radio signal propagation (code measurements) or from phase incursion of a carrier radio wave (phase measurements). When propagating in the ionosphere, navigation radio signals experience a delay whose duration is proportional to TEC along the propa- 
gation direction. This allows us to determine TEC from GNSS measurements. TEC is one of the important characteristics of the ionosphere; it represents the electron density $N_{\mathrm{e}}$ integrated along a certain radio path:

$$
I=\int_{0}^{D} N_{\mathrm{e}} d r .
$$

Thus, TEC is equal to the number of electrons in a column of unit cross-section. TEC variations, as well as $N_{\mathrm{e}}$ variations, reflect the behavior of ionospheric plasma. They can be calculated both from phase and code navigation measurements at two frequencies, as well as from phase and code measurements at one frequency [Hofmann-Wellenhof et al., 1992, 2008; Afraimovich, Perevalova, 2006]. In ionospheric studies, dual-frequency phase measurements are usually used to calculate TEC as more precise. GNSS measurements of phase incursion of a carrier radio wave are carried out with a high degree of accuracy so that the error in determining TEC with $30 \mathrm{~s}$ averaging intervals does not exceed $10^{14} \mathrm{~m}^{-2}$ (or 0.01 TECU, 1 TECU $=10^{16}$ $\mathrm{m}^{-2}$ ) [Hofmann-Wellenhof et al., 1992]. This allows us to detect rather weak disturbances of ionospheric plasma.

TEC variations are calculated from phase measurements by a formula uniform for all GNSS [HofmannWellenhof et al., 1992, 2008]

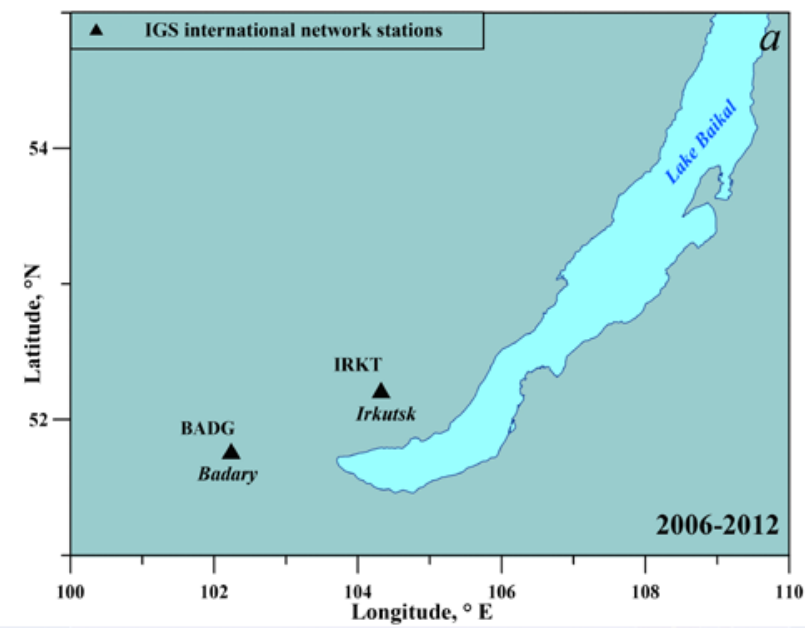

$$
I=\frac{1}{40.308} \frac{f_{1}^{2} f_{2}^{2}}{f_{1}^{2}-f_{2}^{2}}\left(L_{1} \lambda_{1}-L_{2} \lambda_{2}\right),
$$

where $L_{1}, L_{2}$ are increments of radio signal phase path for $f_{1}$ and $f_{2}$, which are caused by the delay in the ionosphere and measured by a GNSS receiver; $\lambda_{1}, \lambda_{2}$ are radio signal wavelengths with $f_{1}$ and $f_{2}$.

Being an integral, TEC cannot be associated with a certain height. It has been established, however, that the ionospheric region which makes the main contribution to TEC and TEC variations is located in the vicinity of the main ionization maximum (F2 region). Therefore, in the first approximation, it is widely accepted that TEC is formed at an ionospheric point - a point of intersection of a GNSS receiver-satellite path with a thin layer located at a height of the F2-layer maximum $h_{\max }$. Coordinates of the ionospheric point are determined from navigation satellite and receiver coordinates [Afraimovich, Perevalova, 2006]. In some studies, it was assumed that $h_{\text {max }}=400 \mathrm{~km}$, which corresponds to the height of the Progress CS flight [Khakhinov et al., 2011, 2012; Khakhinov et al., 2012].

We examine the ACE-induced ionospheric disturbances by analyzing TEC variations calculated with a unified method developed at ISTP SB RAS [Afraimovich, Perevalova, 2006].

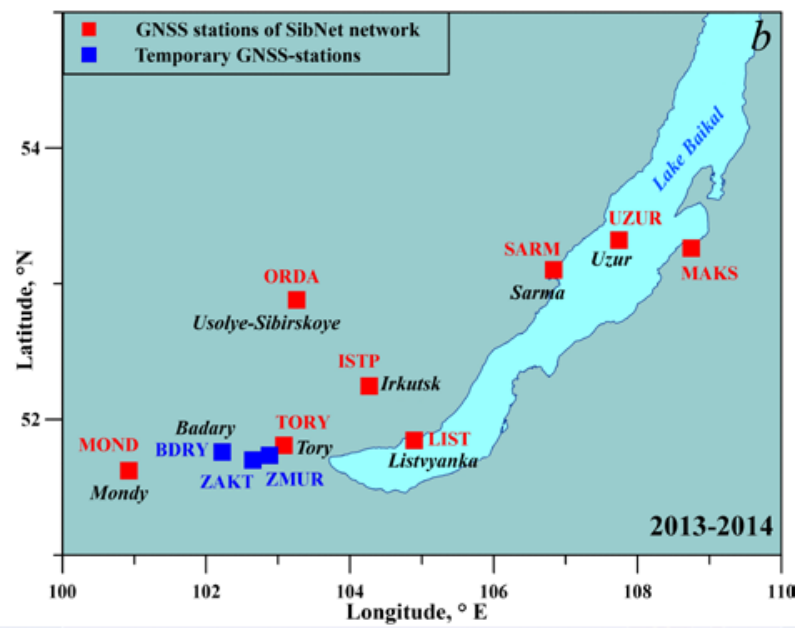

Figure 1. Positions of ground dual-frequency GLONASS/GPS receivers in Siberia during active experiments in 2006-2012 (a) and 2013-2014 (b)

The analysis is based on GPS and GLONASS measurements. TEC variations are calculated from phase measurements at two GNSS carrier frequencies (1). To identify disturbances caused by the operation of CS engines, we filter the resulting series of TEC variations $I(t)$ over a period $2-10 \mathrm{~min}$ for the experiments of 2006-2012 and 0.5-10 min for the experiments of 2013-2014, using the moving average method. As a result, we obtain filtered series of TEC variations $d I(t)$, reflecting dynamics of ionospheric disturbances in the given periods. The filtering range has been selected based on many years of GNSS data processing experience: TEC disturbances with periods 1-10 $\mathrm{min}$ are usually observed during space launchings, explosions, and earthquakes [Afraimovich, Perevalova, 2006]. To assess the level of TEC background fluctuations occurring during the passage of a satellite-receiver radio path near a disturbed region, we calculate rms of the filtered TEC variations for \pm 1 hr relative to the period of impact. The experiments of 2006-2012 used data from the International GNSS Service (IGS) [http://sopac.ucsd.edu ]. The experiments of 20132014 employed data from permanent and temporary stations of the GNSS network SibNet [Ishin et al., 2017 ].

To detect TEC responses to the operation of CS engines, we adopt the method of mapping TEC disturbances, which proved to be very useful in preprocessing of data from the active space experiments [Ishin et al., 2017]. According to this method, the position of ionospheric points of all receiver-satellite 
paths is mapped for a given time; the color of the points corresponds to the amplitude of TEC variations recorded along this path and reflects the level of ionospheric disturbances. The sequence of maps for adjacent time points allows us to trace the spatiotemporal dynamics of TEC disturbances.

\section{EXPERIMENTAL RESULTS FOR 2006-2012 FROM IGS DATA}

The experiments of 2006-2012 used data from two GNSS stations BADG and IRKJ included in IGS. The BADG station is located in the Radio Astronomy Observatory Badary of the Institute of Applied Astronomy of the Russian Academy of Sciences (the Badary area, Tunka valley) [http://www.ipa.nw.ru]. The IRKJ station is located on the territory of the Astrogeodynamic Observatory of the East Siberian Branch of FSUE (VNIIFTRI) [http://www.vniiftri-irk.ru] in Irkutsk (Figure 1, a). BADG and IRKJ measurement data were taken from the IGS website [http://sopac.ucsd.edu]. Time resolution of the data is $30 \mathrm{~s}$.

In 2006-2012, $37 \mathrm{SE}$ sessions were processed. In 35 cases, a TEC response to the CS ACE impact was not detected. Figure 2 shows a typical example of the experiment geometry and time variations of TEC for the April 23, 2012 event, which demonstrates the absence of TEC response to the CS ACE impact.

In Figure 2, $a$, the thick line indicates the CS trajectory (the thickened section marks spacecraft with ACE running). Triangles are IRKJ and BADG stations; thin black lines with arrows are trajectories of ionospheric points: dashed lines are GPS satellites (G), solid lines are GLONASS satellites (R). Circles on the trajectories indicate positions of the ionospheric points during ACE operation (10:38:30 UT). The color shows respective TEC variations (the color scale is shown below). The trajectories are given for an interval of \pm 30 min from the

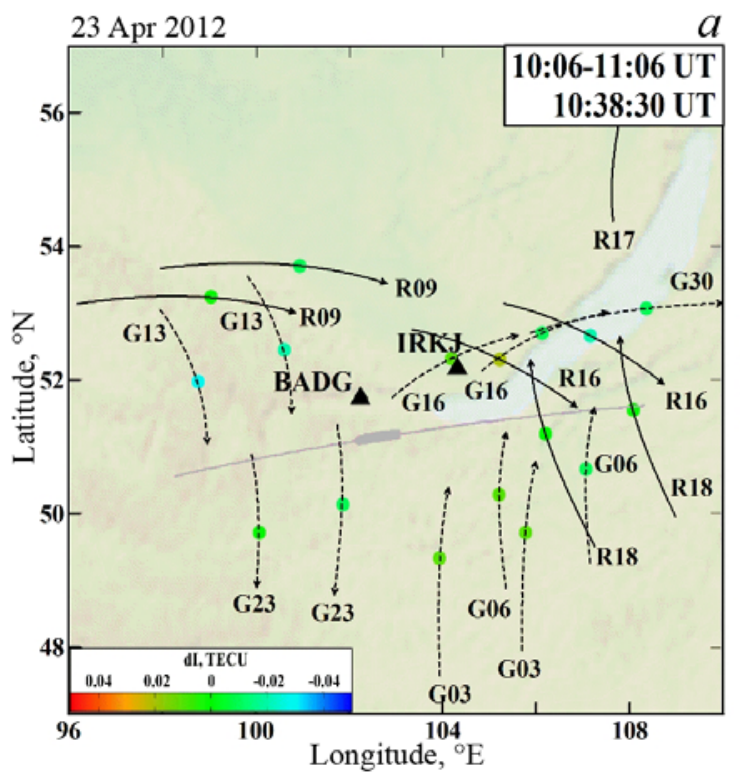

operation time of ACE (10:06-11:06 UT). Figure 2, $b$ displays filtered TEC variations corresponding to three ionospheric points for BADG-R18 (black line) and IRKJ-G23 (gray line), which turned out to be closest to the flight path. The dashed vertical line shows the time of engine start.

When engines were running, all ionospheric points were far away (at least 50-100 km) from the CS trajectory (Figure. 2, a). Time TEC variations exhibit background oscillations masking a possible TEC response to the operation of ACE. In particular, along the BADGR18 path (Figure 2, b) there are intense quasioscillations of TEC, which cannot be considered a response to the operation of CS ACE. This is evidenced by the remoteness of the ionospheric point from the disturbed region, as well as by the fact that the observed quasi-oscillations occur both after CS passage and before it. These oscillations are disturbances generated by other sources. The remoteness of the ionospheric points from the disturbed region and the presence of the intense background oscillations made it impossible to detect a strong TEC disturbance generated by the CS ACE impact. A similar situation was observed in most (35) SE sessions.

In two sessions, due to the simultaneous analysis of time TEC variations and dynamics of TEC disturbance maps, we managed to detect possible TEC responses to the ACE impact: on May 4, 2006 and April 24, 2011. Parameters of the responses are given in Table. In both the cases, geomagnetic conditions were quiet: the $K_{\mathrm{p}}$ index did not exceed 2.7 (see Table), which facilitated identification of the responses. Figure 3 shows the experiment geometry and filtered TEC variations for the CS flight on May 4, 2006. Notations are the same as in Figure 2. The map of TEC disturbances (Figure 3, $a$ )

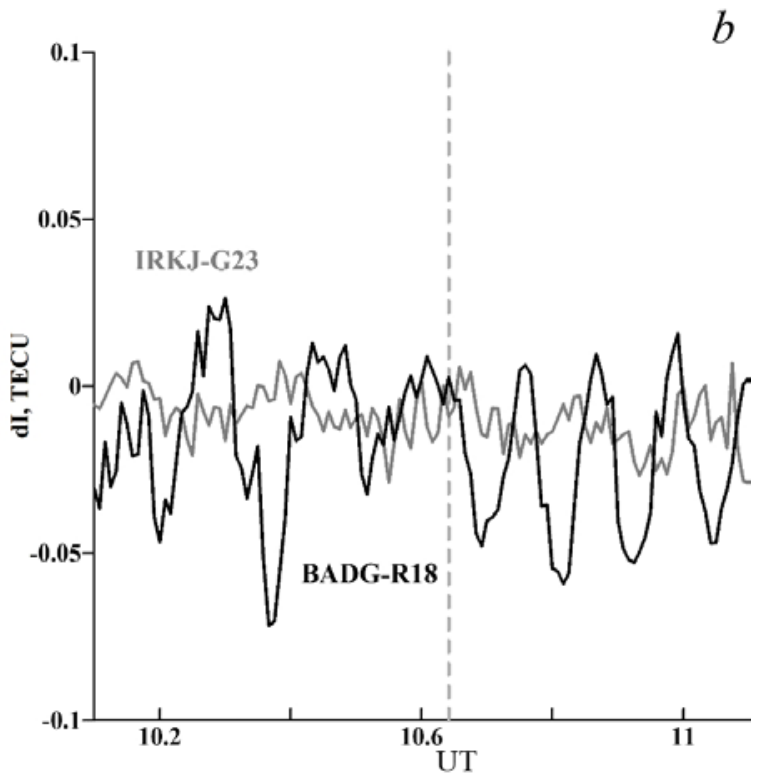

Figure 2. Geometry of measurements (a) and corresponding filtered TEC variations $(b)$ during the April 23, 2012 experiment. For each satellite, two tracks of ionospheric points are shown: to the west is for the BADG station; to the east, for the IRKJ station 

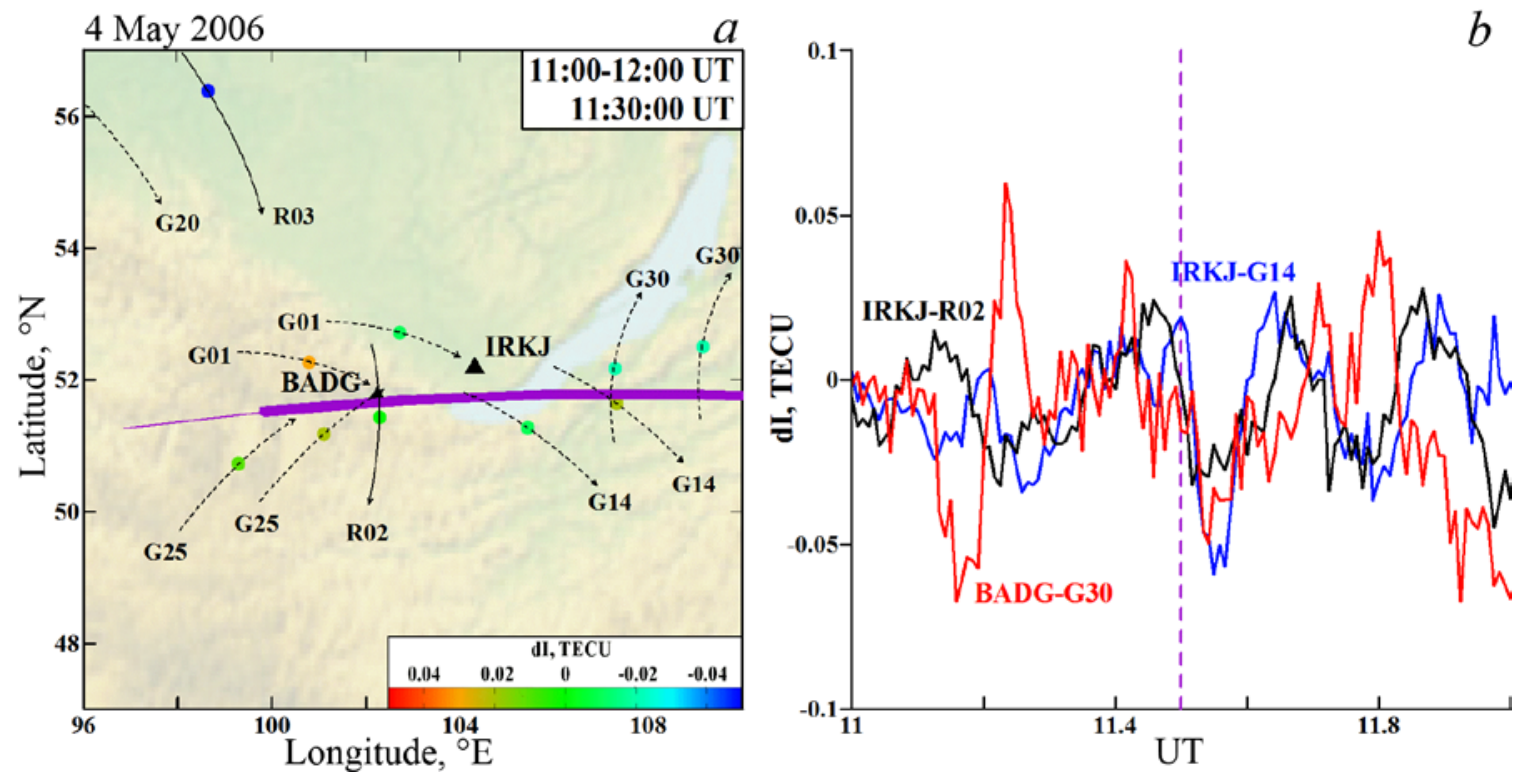

Figure 3. Geometry of measurements (a) and corresponding filtered TEC variations (b) during the May 4, 2006 experiment

Parameters of TEC responses to the CS ACE impact

\begin{tabular}{|c|c|c|c|c|c|c|c|c|}
\hline Date & $\begin{array}{l}\text { Time of } \\
\text { impact } \\
\text { (UT) }\end{array}$ & $\begin{array}{c}K_{\mathrm{p}} \text { index for } \\
\text { previous } \\
6 \mathrm{hrs}\end{array}$ & Radio path & \begin{tabular}{|l} 
Start time of \\
recording \\
after ACE \\
ignition, min \\
\end{tabular} & \begin{tabular}{|c|} 
RMS \\
of 2-hr series \\
of TEC varia- \\
tions, TECU \\
\end{tabular} & $\begin{array}{l}\text { Duration, } \\
\text { min }\end{array}$ & $\begin{array}{l}\text { Ampli- } \\
\text { tude, } \\
\text { TECU }\end{array}$ & \begin{tabular}{|c|} 
Transverse \\
(meridional) \\
size \\
of region, km \\
\end{tabular} \\
\hline \multirow{3}{*}{$\begin{array}{c}\text { May 04, } \\
2006\end{array}$} & \multirow{3}{*}{$11: 29$} & \multirow{3}{*}{$2-2.7$} & IRKJ-G14 & 1 & 0.021 & 4.5 & 0.06 & 19 \\
\hline & & & IRKJ-R02 & 1 & 0.015 & 6 & 0.03 & 25 \\
\hline & & & BADG-G30 & 1 & 0.24 & 5.5 & 0.05 & 22 \\
\hline $\begin{array}{c}\text { April 24, } \\
2011\end{array}$ & 13:51 & $0.7-1.3$ & IRKJ—G07 & 0.5 & 0.036 & 4 & 0.11 & 12 \\
\hline $\begin{array}{c}\text { April 18, } \\
2013\end{array}$ & $12: 28$ & 0.3 & ORDA-G07 & 5 & 0.018 & 4.5 & 0.06 & 17 \\
\hline \multirow{3}{*}{$\begin{array}{c}\text { June 16, } \\
2013\end{array}$} & \multirow{3}{*}{$12: 38$} & \multirow{3}{*}{$0.3-0.7$} & BDRY-G17 & 14 & 0.023 & 4 & 0.07 & 13 \\
\hline & & & ZAKT-G17 & 12 & 0.025 & 6.5 & 0.06 & 21 \\
\hline & & & ZMUR-G17 & 12 & 0.025 & 8 & 0.04 & 26 \\
\hline $\begin{array}{c}\text { June 18, } \\
2013 \\
\end{array}$ & $12: 22$ & $0.3-0.7$ & UZUR-R10 & 0.5 & 0.082 & 10 & 0.12 & 30 \\
\hline \multirow{2}{*}{$\begin{array}{c}\text { April 16, } \\
2014\end{array}$} & \multirow{2}{*}{$12: 09$} & \multirow{2}{*}{$0.7-1.3$} & LIST-G08 & 4 & 0.033 & 6 & 0.07 & 22 \\
\hline & & & ORDA-R17 & 5 & 0.022 & 3 & 0.16 & 15 \\
\hline $\begin{array}{c}\text { July 29, } \\
2014 \\
\end{array}$ & 19:09 & $0.7-1$ & TORY-G22 & 8 & 0.031 & 5 & 0.12 & 16 \\
\hline
\end{tabular}

is shown for the time point corresponding to the minimum TEC variations caused by the CS ACE impact.

Figure 4 shows a set of successive maps of TEC disturbances for the May 4, 2006 experiment. The thick line indicates the trajectory of the CS flight with ACE running; the thin line, with ACE turned off. Dashed lines denote ionospheric points corresponding to IRKJR02 (single point), IRKJ-G14 and BADG-G30 (twopoint group).

The analysis of the dynamics of the TEC disturbance maps has revealed a sharp and significant decrease in TEC variations $1 \mathrm{~min}$ after the CS ACE start along IRKJ-G14, IRKJ-R02, and BADG-G30 radio paths (Figure 4). This is confirmed by the nature of time variations in TEC (Figure 3, b): along all the three radio paths immediately after the CS passage, there are $~ 6-10$ min minima with amplitude from 0.02 to 0.05 TECU. The response amplitude exceeds both the error in determining TEC (0.01 TECU) and the level of back- ground variations ( $\sim 0.025$ TECU) observed at close satellite elevation angles (Table). It is noteworthy that, as derived from all the three series, these minima occur practically simultaneously and are similar in shape. Despite only two ionospheric points (IRKJ-G14 and BADG-G30) being near each other ( 50 km), and the third (IRKJ-R02) being more than $400 \mathrm{~km}$ away from them, all the three points are at $10-40 \mathrm{~km}$ from the section of the trajectory of the spacecraft with engine running. This allows us to conclude that there is a relationship between the detected minimum of TEC variations and the CS engine operation. The analysis of the TEC series for other GNSS receiver-satellite radio paths have not revealed any changes related to the CS impact because these paths passed away (more than $50 \mathrm{~km}$ ) from the active section of the CS trajectory.

Similar results were obtained during the April 24, 2011 experiment. The analysis of the dynamics of TEC disturbance maps has shown a sharp and significant decrease 

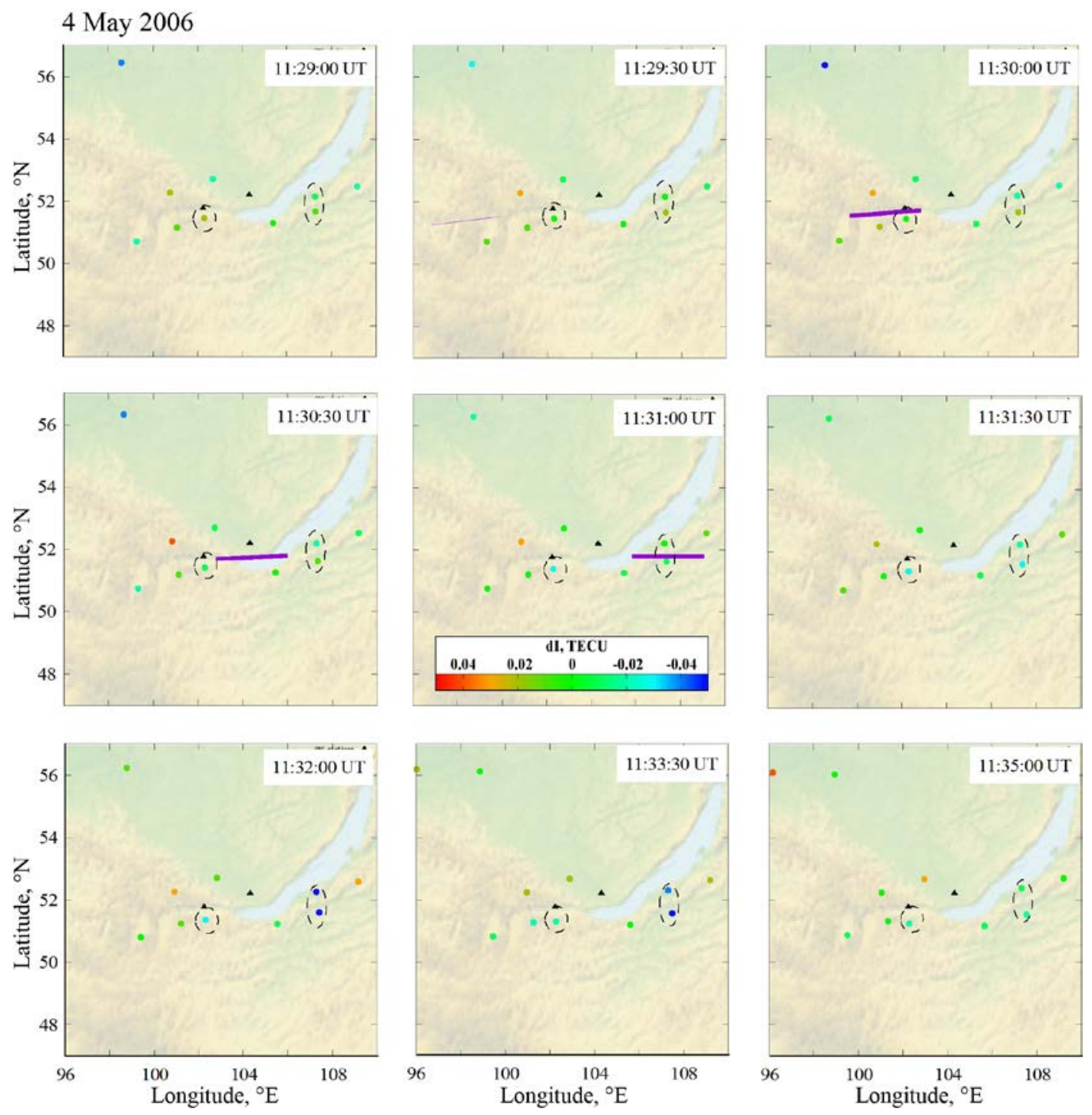

Figure 4. Dynamics of TEC disturbance maps during the May 4, 2006 experiment. Triangles mark GNSS stations. The color of the ionospheric points indicates the instantaneous TEC variations for a current radio path. The solid line is the trajectory of Progress CS with engines running (in a respective interval)

decrease in TEC variations $30 \mathrm{~s}$ after the CS ACE start along the IRKJ-G07 radio path. The ionospheric point of this radio path was located at a distance of $\sim 10 \mathrm{~km}$ from the section of the trajectory of CS with ACE running. In corresponding time variations of TEC, immediately after the CS passage, there was a $\sim 3-5$ min minimum with amplitude of more than 0.1 TECU (with a background oscillation level of 0.025 TECU, Table).

Thus, the two IGS stations detected the response in two of 37 experiments. The limited number of effective experiments is associated with a small number of stations in the region of the experiment; therefore, ionospheric points rarely intersected the disturbed region.

\section{EXPERIMENTAL RESULTS FOR 2013-2014 FROM SIBNET DATA}

In 2012, ISTP SB RAS SibNet permanent GNSS stations began regular observations [Ishin et al., 2017]. Therefore, the experiments of 2013-2014 were based on data from this network (Figure 1, b). In addition, during the experiments, the network of permanent stations was supplemented with a network of temporary observation points (Figure 1, b) [Ishin et al., 2017]. Thus, during the SE sessions of 2013-2014, the configuration of SibNet had the form shown in Figure 5, 6.

In 2013-2014, 35 SE sessions were processed. Five of them confidently showed a response in TEC variations to the CS impact. Parameters of the responses are given in Table. There were no strong geomagnetic disturbances on observation days: the $K_{\mathrm{p}}$ index did not exceed 1.3 for 6 hrs before the experiments.

The analysis of ionospheric maps has showed that the response in TEC variations is recorded when the ionospheric point passes near the affected region within a few minutes after the CS passage. When the ionospheric point intersected the disturbed region, negative TEC disturbances occurred. An example of such a disturbance is given in Figure 7 for the April 18, 2013 experiment. The ionospheric point of the ORDA-G07 path crosses the disturbed region 7 minutes after the CS passage. The time series of TEC along this path 
clearly show a sharp decrease in TEC (Figure 8, ORDA). At the same time, there is no similar decrease in TEC at all other stations (Figure 8, $c$ ). Note that at 12:29 for the G07satellite, all stations simultaneously recorded a positive increase in TEC (Figure 8, c). Such TEC increase is a well-known phenomenon and occurs due to a cycle slip [Hofmann-Wellenhof et al., 1992, 2008]. In our case, there are strictly synchronous increases for one satellite at all operating stations. They are caused by failure (phase jump) in the operation of satellite transmitting equipment.
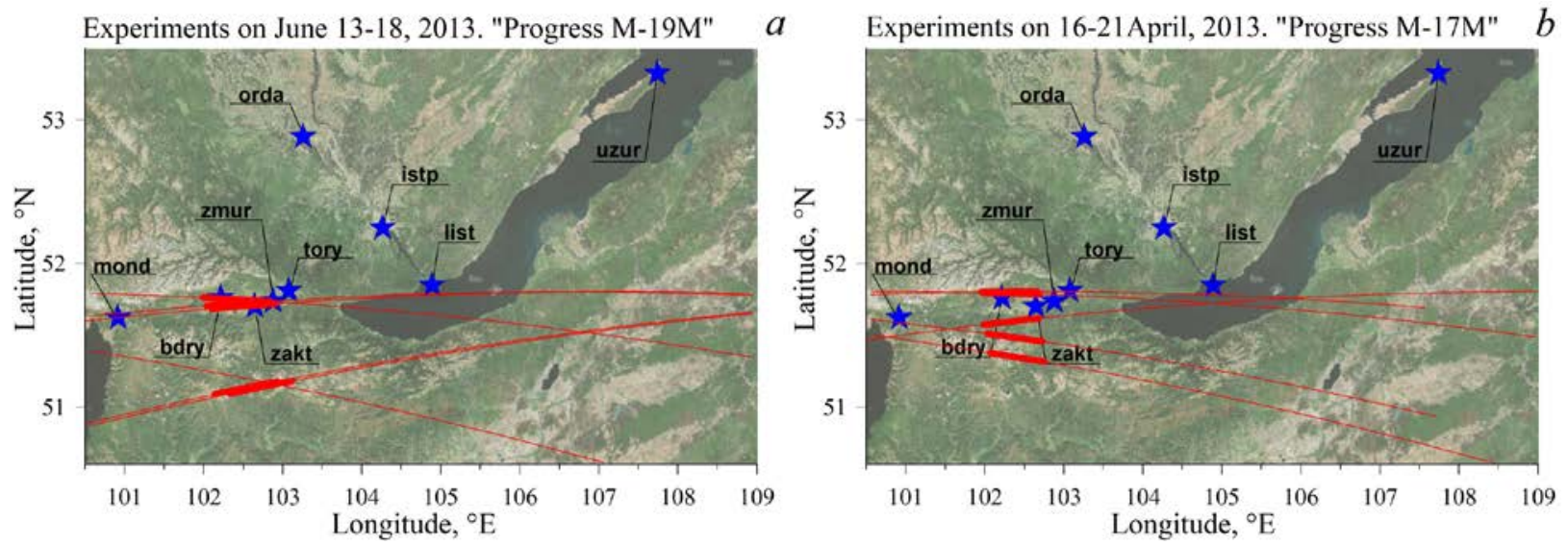

Figure 5. Geometry of the experiments of 2013 for SibNet. Asterisks are GLONASS/GPS stations; lines are trajectories of Progress-17 (April) and Progress-19 (June)
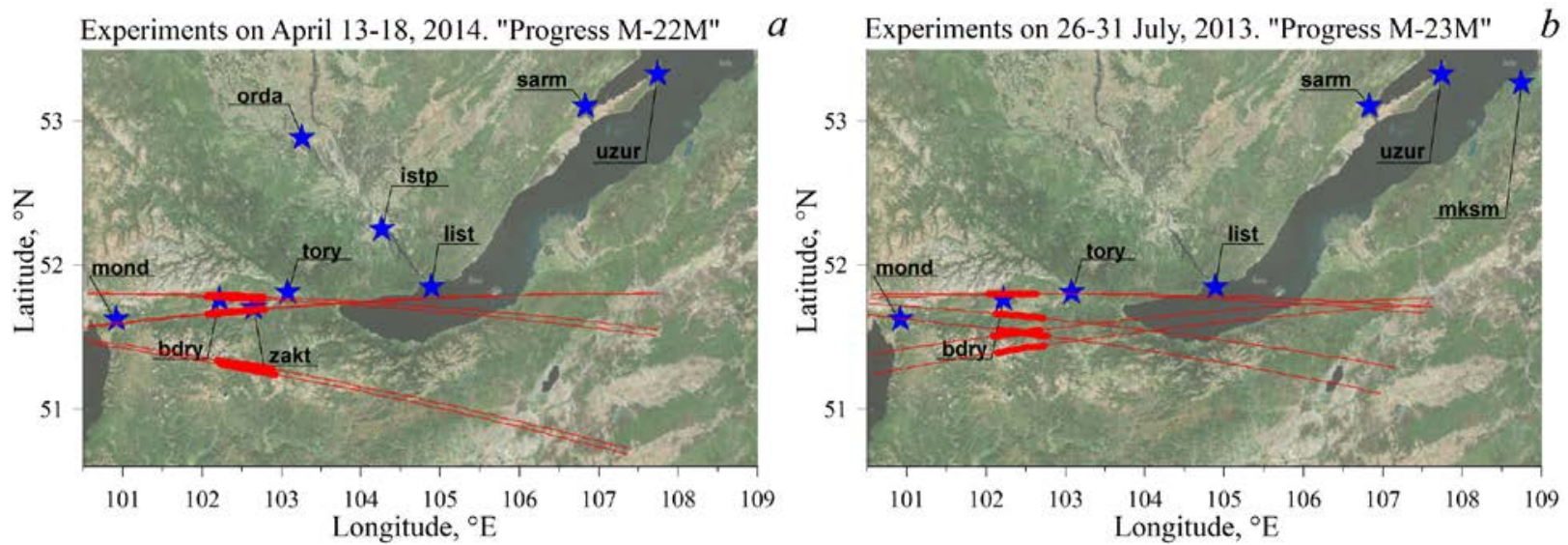

Figure 6. Geometry of the experiments of 2014 for SibNet. Asterisks are GLONASS/GPS stations, lines are trajectories of Progress-21 (April) and Progress-23 (July)
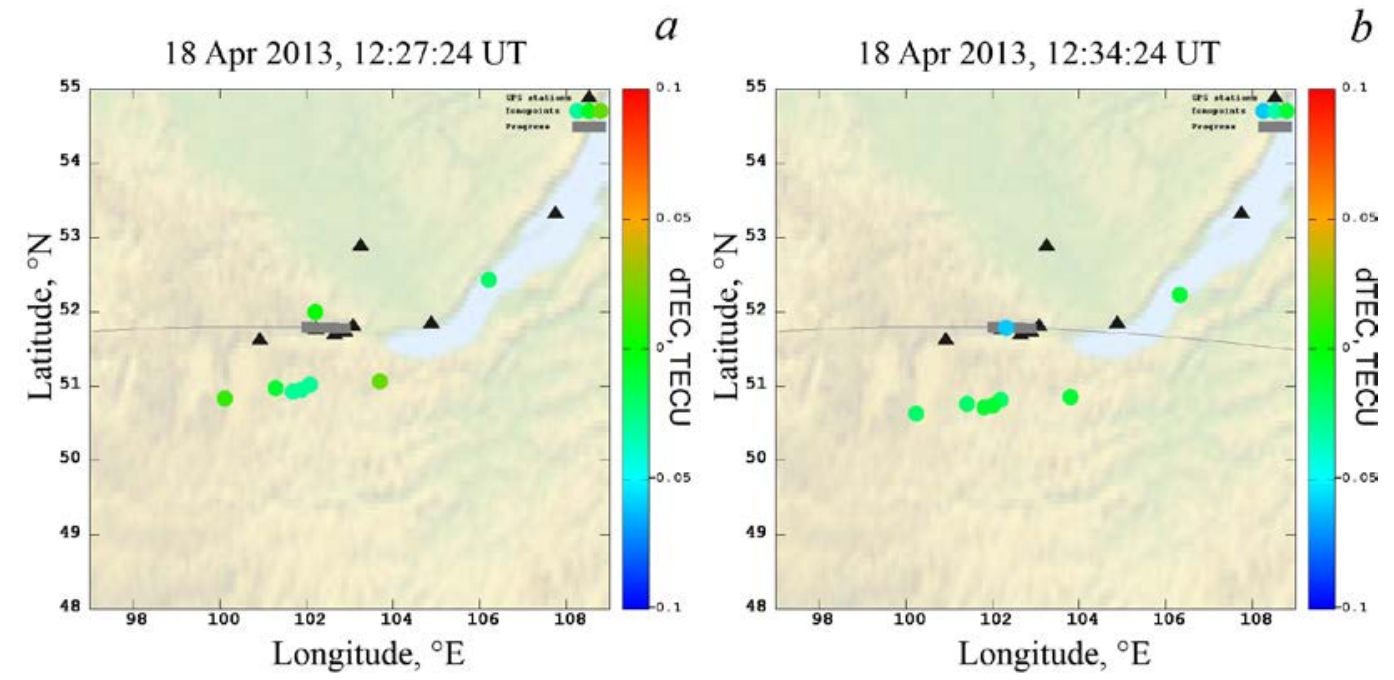

Figure 7. Ionospheric points for the GPS G07 satellite during the April 18, 2013 experiment. The color shows TEC variations along the corresponding satellite-receiver radio path. Triangles are GLONASS/GPS stations, the line is the Progress CS trajectory; a thickened section of the trajectory indicates the movement of the Progress CS with engine running 
The most interesting case is the detection of a negative TEC disturbance during the April 16, 2014 experiment. Preliminary results obtained with GPS (LIST-G08 radio path) for this event are reported in [Ishin et al., 2017]. Even more representative results of recording of this disturbance were obtained from GLONASS data. In this experiment, the ionospheric point for GLONASS satellite No. 17 at ORDA (ORDA-R17 radio path) crossed the disturbed region 6 minutes after the Progress CS engine start (Figures 9, 10). The dynamics of TEC variations in the ionospheric points of GLONASS satellite No. 17 allows us to directly detect a TEC decrease when the ionospheric point of the ORDA-R17 radio path intersects the disturbed region (Figure 10).

Respective time variations of TEC for GLONASS/GPS stations are shown in Figure 11. Along the ORDA-R17 radio path there is a negative TEC disturbance with amplitude of 0.16 TECU. Duration of the recording of this disturbance did not exceed $2 \mathrm{~min}$. Note that the ORDA station is located at the ISTP SB RAS Observatory of Radiophysical Diagnostics of the Atmosphere. The Progress CS jet stream in the April 16, 2014 experiment was directed toward this observatory.

Presumably, this facilitated the recording of such a short but pronounced intense disturbance.

In general, the SibNet permanent and temporary stations have detected TEC responses to the CS ACE impact in 5 SE sessions: on April 18, 2013, June 16 and 18, 2013, April 16, 2014, July 29, 2014. Generalized parameters of the responses are given in Table.

\section{ANALYSIS OF THE RESULTS}

Ionospheric disturbances generated by CS ACE in the 2006-2014 SE have been studied by analyzing TEC variations. TEC data were obtained from the GLONASS/GPS network located in the Baikal region: the International GNSS Service (IGS) (experiments of 2006-2012), the network of ISTP SB RAS stationary GLONASS/GPS stations (SibNet) with temporary GLONASS/GPS stations (experiments of 2013-2014). TEC variations were calculated from GLONASS/GPS data with a unified method.

Geomagnetic conditions during the experiments can be characterized as quiet. Only once (on May 4, 2006), $K_{\mathrm{p}}$ reached 2.7 for 6 hrs before the experiment. In other cases, $K_{\mathrm{p}}$ was below 1.3 (see Table).

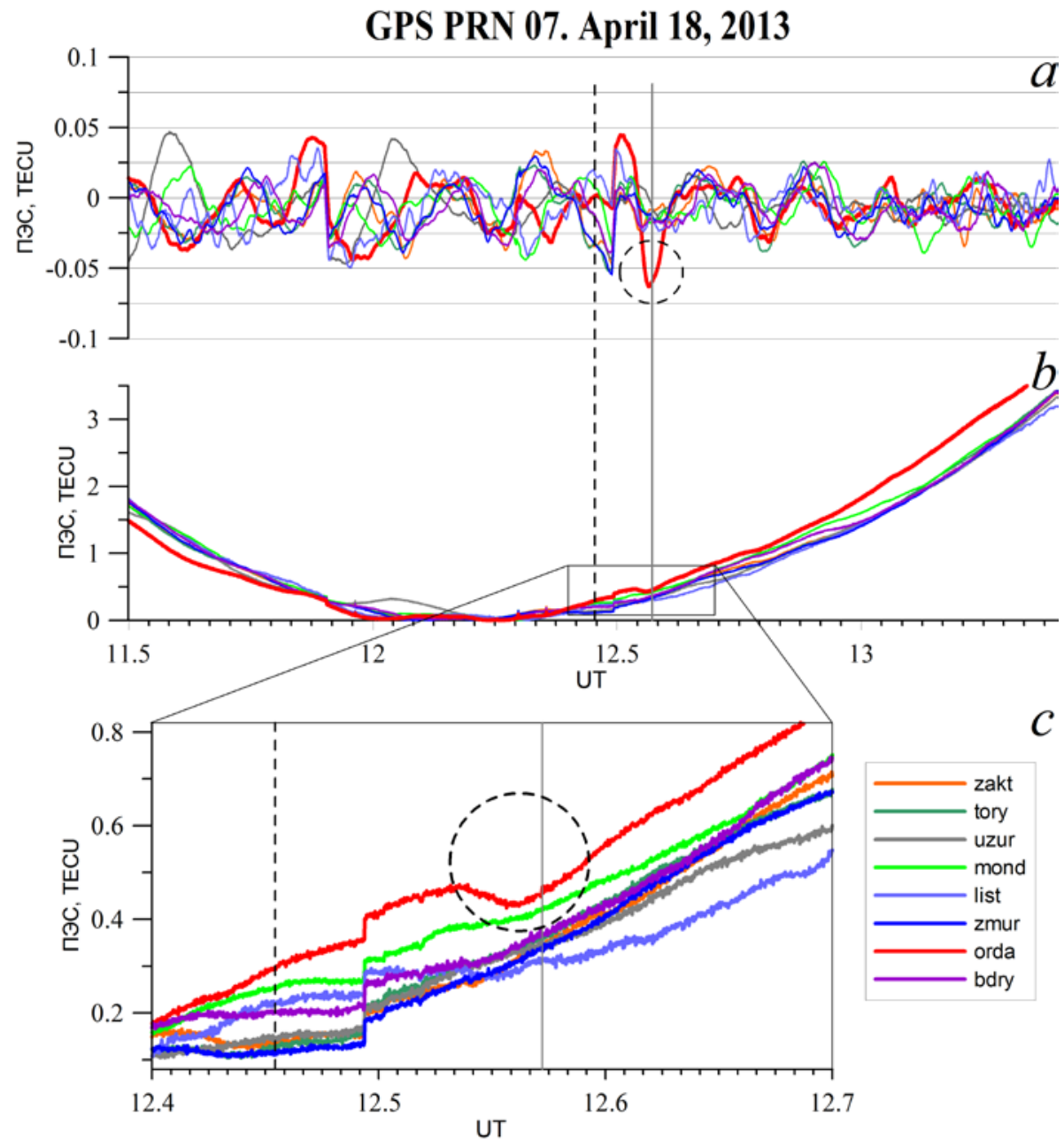

Figure 8. TEC variations for the GPS G07 satellite filtered in a range $0.5-10 \mathrm{~min}(a)$ and unfiltered $(b, c)$ for different stations. The vertical dashed line indicates the moment of ACE ignition, the vertical solid line is the moment when the ionospheric point of the ORDA-G07 radio path intersects the Progress CS trajectory 
Satellite 17 GLONASS, April 16, 2016

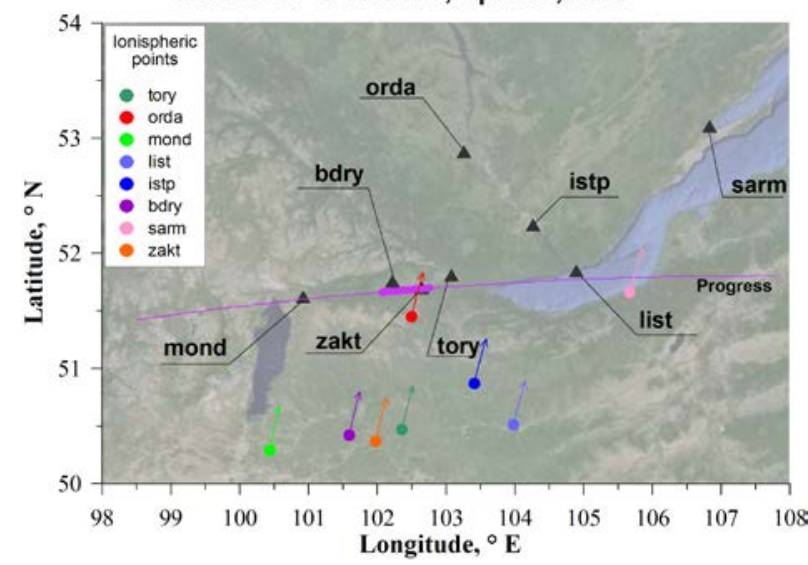

Figure 9. Position of ionospheric points for GLONASS satellite No. 17 during the April 16, 2014 experiment. Arrows show trajectories of ionospheric points within $10 \mathrm{~min}$ after the CS ACE start; triangles are GLONASS/GPS stations

Over the entire period of SE, 72 Progress CS passages have been processed. In 65 of them, there was no response recorded in TEC variations to the CS ACE impact. The identification of TEC response to the operation of CS ACE from GLONASS/GPS data is complicated by a number of factors: strong spatial localization and low intensity of ionospheric disturbance; integral character of TEC measurements; a small number of GLONASS/GPS stations and, accordingly, a receiversatellite radio paths; presence of background ionospheric disturbances of different intensities.

The TEC response to the CS operation has been found in 7 of 72 SE sessions (i.e. in $10 \%$ of observations). As follows from the description given in the previous two sections, the TEC response was detected at radio paths that passed in the immediate vicinity of the ionosphere region, disturbed by the CS impact, or crossed this region. The geometry of the experiments was such that respective ionospheric points moved predominantly across the CS trajectory. Parameters of the responses are given in Table.

The detected TEC responses represent a decrease in TEC with 3-10 min duration and 0.03-0.16 TECU amplitude. Amplitudes of the responses exceeded the error in determining TEC (0.01 TECU) and the level of background variations at close satellite elevation angles (see Table). The observed TEC decrease allows us to conclude that ACE operation can causes a decrease in electron density in the disturbed region. The responses are recorded 0.5-6 min after the ACE start.

Knowing the position of an ionospheric point at the beginning and end of recording of a TEC response to the CS ACE operation, we can estimate the size of the disturbed region in the meridional direction, i.e. across the CS trajectory. The estimation was carried out under the assumption that ionospheric points intersect an ACE-disturbed region, which moves predominantly in the latitudinal direction and is practically immobile in the meridional direction. The size of the disturbed region was calculated as a distance along the great-circle arc between the above two positions of the ionospheric point. Table lists the calculated transverse dimensions of the region disturbed by the CS ACE operation, which are $\sim 12-30 \mathrm{~km}$. Note that the small number of ionospheric points and their displacement due to the motion of a navigation satellite do not allow us to trace the expansion of the disturbed region.

\section{CONCLUSIONS}

The analysis of space-time TEC variations observed during active SE in 2006-2014 has shown that the problem of detecting TEC responses to CS ACE impact is complicated by a number of factors. The impact of jet engines on ionospheric plasma is strongly localized in space and has a relatively low intensity. The integral nature of TEC measurements impedes the identification of such disturbances. A small number of receiversatellite radio paths caused by the limited number of GLONASS/GPS stations (especially until 2013) significantly reduces the probability of detecting localized disturbances. A possible TEC response is masked with background ionospheric disturbances of different intensities.

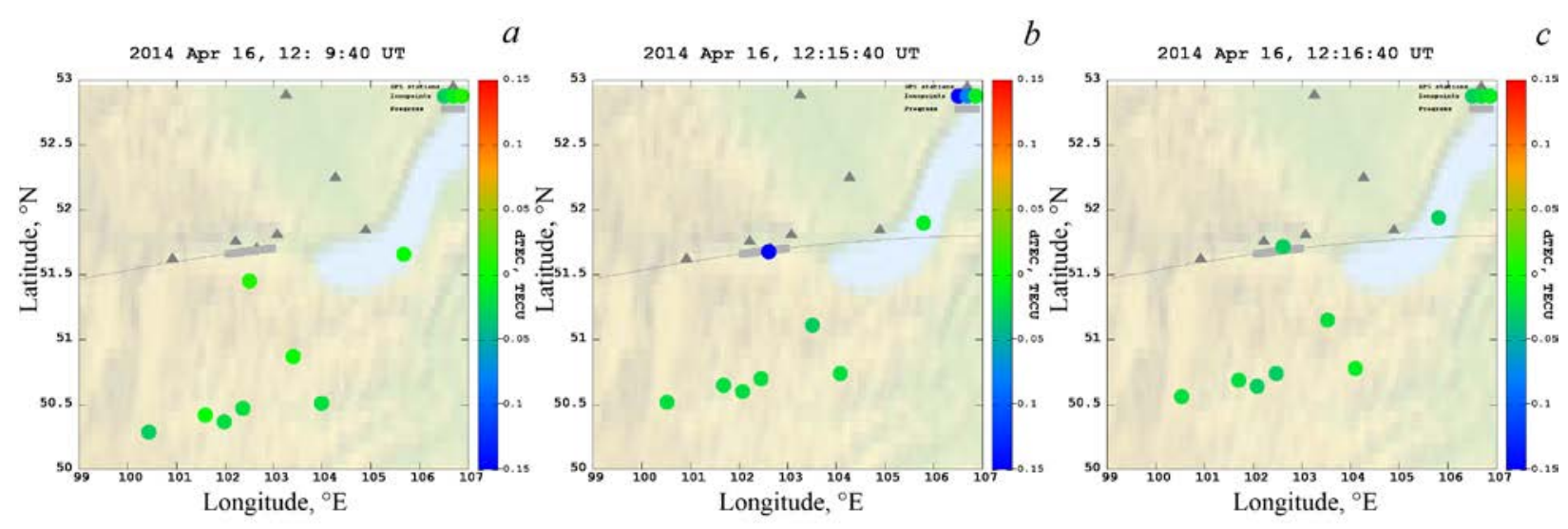

Figure 10. Movement of ionospheric points for GLONASS satellite No. 17 within 7 min after the CS ACE start. The color indicates TEC variations. The gray line is the Progress CS trajectory; the thickened section of the trajectory is the Progress CS with ACE running 
Satellite 17 GLONASS. April 16, 2014

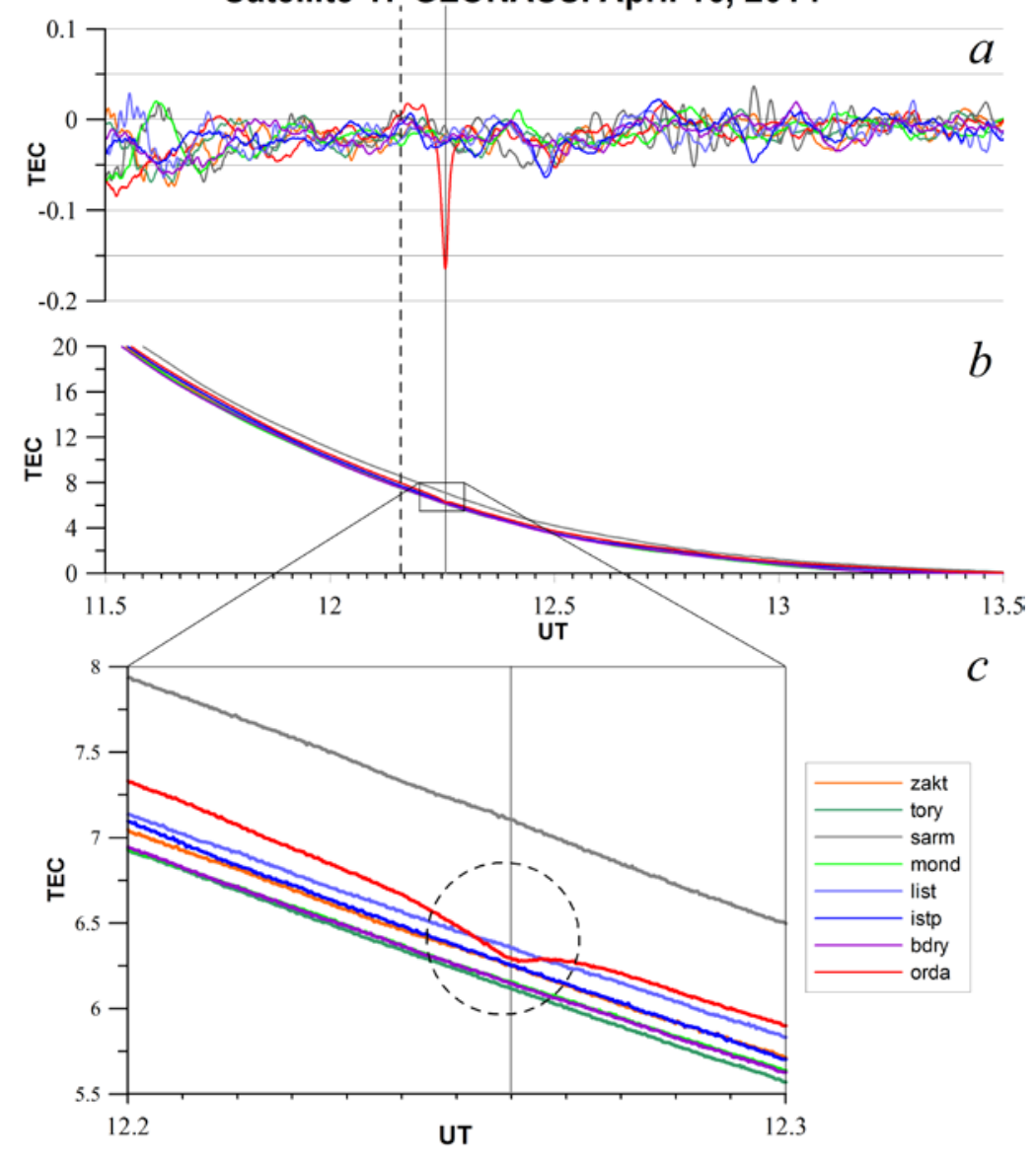

Figure 11. TEC variations for GLONASS satellite No. 17 filtered in the range $0.5-10$ min $(a)$ and unfiltered $(b, c)$ for different stations. The vertical dashed line is the moment of the CS ACE ignition; the vertical solid line is the moment when the ORDA-R17 ionospheric point crossed the trajectory of CS with ACE running

On the other hand, with a successful geometry of experiment, a receiver-satellite radio path can cross the disturbed region within the next few minutes after the impact. Here, the amplitude of the ionospheric response to the CS ACE start is several times higher than the background TEC variations under quiet geomagnetic conditions. In this case, we can estimate both the amplitude of TEC variations and the transverse size of the observed irregularity. For this estimation, we should take into account that the irregularity does not remain static but increases in spatial dimensions, with amplitude of negative disturbance becoming low.

Specific estimates of the electron density decrease are beyond the scope of this article. Preliminary estimates made with a simple TEC disturbance model have been made in [Ishin, Voeikov, 2017]. More accurate estimates can be made with the use of data from other registering instruments working during the same experiments. Determination of these values is the task for future investigations.

We are grateful to V.P. Lebedev for providing us with data on Progress CS passages. The work was carried out under project No. AAAA-A16-1160122104600 "Investigation of the lithosphere-atmosphereionosphere system under extreme conditions" of RAS Presidium Program No. 15. The work was supported by RFBR grant No. 16-35-00027_mol_a "Studying ionospheric response to simultaneous influence of various sources in the neutral atmosphere” for 2016-2017. Experimental data were obtained with the Angara Multiaccess Center facilities at ISTP SB RAS.

\section{REFERENCES}

Afraimovich E.L., Perevalova N.P. GPS-monitoring verhnej atmosfery Zemli [GPS-monitoring of the Earth's upper atmosphere]. Irkutsk, 2006. 480 p.

Borisov B.S., Gabdullin F.F., Garkusha V.I., Korsun A.G., Kurshakov M.Yu., Strashinskiy V.A., Tverdokhlebova E.M., Khakhinov V.V. Radiophysical characteristics of low-orbit spacecraft plasma environment revealed by space experiments. Nelineinyi mir [J. Nonlinear World]. 2012, vol. 10, no. 10, pp. 700-709. (In Russian).

Hofmann-Wellenhof B., Lichtenegger H., Collins J. Global Positioning System: Theory and Practice. New York, Wien, Springer-Verlag, 1992, $327 \mathrm{p}$.

Hofmann-Wellenhof B., Lichtenegger H., Wasle E. GNSS Global Navigation Satellite Systems: GPS, GLONASS, Galileo and more. New York, Wien, Springer, 2008, 516 p.

Institut solnechno-zemnoj fiziki: sozdanie i razvitie. Ed. Zherebtsov G.A. [Institute of Solar-Terrestrial Physics: Foundation and Development. Ed. Zherebtsov G.A.]. Novosibirsk, SB RAS Publ., 2015. 610 p. (In Russian).

Ishin A.B., Voeykov S.V. Determination of the ionospheric response parameters to the engine operation of spaceship "Progress" according to GNSS data Proc. XXIII International Symp. "Atmospheric and Ocean Optics. Atmospheric Physics”. Irkutsk, July 3-7, 2017, pp. E85-E88. (In Russian).

Ishin A.B., Perevalova N.P., Voeykov S.V., Khakhinov V.V. 
First results of registering the ionospheric disturbances according to SibNet network of GNSS receivers in active space experiments. Solnechno-zemnaya fizika [Solar-Terr. Phys.]. 2017, vol. 3, iss. 4, pp. 82-92. DOI: 10.12737/szf-34201708. (In Russian).

Khakhinov V.V., Potekhin A.P., Lebedev V.P., Medve$\operatorname{dev}$ A.V., Kushnarev D.S., Shpynev B.G., Zarudnev V.E., Alsatkin S.S., Ratovsky K.G, Podlesny A.V., Bryn’ko I.G. Radio physical methods of diagnostics of the ionospheric disturbances generated by onboard engines of TCS "Progress": algorithms, tools and results. Zhurnal radioelektroniki. Rossiiskaya nauchnaya konferentsiya "Zondirovanie zemnykh pokrovov radarami s sintezirovannoi aperturoi. Ulan-Ude, 06.09-10.09 2010. [J. Radio Electronics. Proc. The Russian Scientific Conference "Sounding of Terrestrial Covers Using Radars with the Synthesized Aperture. UlanUde, 06.09-10.09, 2010]. 2010, pp. 553-569. (In Russian).

Khakhinov V.V., Potekhin A.P., Lebedev V.P., Alsatkin S.ऽ Ratovsky K.G, Kushnarev D.S., Tverdokhlebova E.M Kurshakov M.Yu., Manzheley A.I., Timofeeva N.I. Results of remote sounding of ionospheric disturbances during active experiments Radar-Progress. Sovremennye problemy distantsionnogo zondirovaniya Zemli iz kosmosa [Current Problem in Remote Sensing of the Earth from Space]. 2012, vol. 9, no. 3. pp. 199-206. (In Russian).

Khakhinov V.V., Potekhin A.P., Lebedev V.P., Kushnarev D.S., Alsatkin S.S. Some results of "Plasma-Progress" and Radar-Progress active space experiments. Vestnik Sibirskogo gosudarstvennogo aerokosmicheskogo universiteta im. akademika M.F. Reshetneva [Bull. Acad. M.F. Reshetnev Siberian State Space University]. 2013, Special Iss., vol. 5, no. 51, pp. 160-162. ISSN: 1816-9724. (In Russian).

Khakhinov V., Potekhin A., Shpynev B., Alsatkin S., Ratovsky K., Lebedev V., Kushnarev D. Results of complex radiosounding of ionospheric disturbances generated by the transport spacecraft Progress onboard thrusters. Proc. $30^{\text {th }}$ URSI General Assembly and Scientific Symp. 2011. URL:
http://www.ursi.org/proceedings/procGA11/ursi/HP215.pdf (accessed 12.05.2017).

Khakhinov V.V., Shpynev B.G., Lebedev V.P., Kushnarev D.S., Alsatkin S.S., Khabituev D.S. Radiosounding of ionospheric disturbances generated by exhaust streams of the transport spacecraft Progress engines. Proc. PIERS2012. Moscow, 2012, pp. 1168-1171.

Lebedev V.P., Khakhinov V.V., Gabdullin F.F., Korsun A.G, Tverdokhlebova E.M., Laletina E.A., Manzheley A.I. Radar Sensing Studies in Plasma Surrounding Characteristics for Low-EarthOrbit Spacecraft. Kosmonavtika i raketostroenie [Cosmonautics and Rocket Engineering]. 2008, vol. 1, no. 50, pp. 51-60. (In Russian).

Potekhin A.P., Khakhinov V.V., Medvedev A.V., Kushnarev D.S., Lebedev V.A., Shpynev B.G. Active space experiments with the use of the transport spacecraft Progress and kutsk IS Radar. Progress in Electromagnetics Research uymp. 2009, pp. 223-227.

Seismoionosfernye i seismoelektromagnitnye protsessy v Bajkal'skoi riftovoi zone. Ed. Zherebtsov G.A. [Seismoionospheric and Seismoelectromagnetic Processes in the Baikal Rift Zone. Ed. Zherebtsov G.A.]. Novosibirsk, SB RAS Publ. 2012, 304 p. (In Russian).

URL: http://sopac.ucsd.edu (accessed 12.05.2017).

URL: http://www.vniiftri-irk.ru (accessed 12.05.2017).

URL: http://www.ipa.nw.ru (accessed 12.05.2017).

How to cite this article

Ishin A.B., Voeikov S.V., Perevalova N.P. Complex analysis of ionospheric response to operation of Progress cargo spacecraft from GNSS data in the Baikal region. Solar-terrestrial physics. 2017. Vol. 3, No. 4, P. 83-92. DOI: 10.12737/stp-34201709 